\title{
SOME INVERSE PROBLEMS FOR CONVECTION-DIFFUSION EQUATIONS
}

\author{
S.G. Pyatkov, Yugra State University, Khanty-Mansyisk, Russian Federation,
} s_pyatkov@ugrasu.ru,

E.I. Safonov, Yugra State University, Khanty-Mansyisk, Russian Federation, dc.gerz.hd@gmail.com

We examine the well-posedness questions for some inverse problems in the mathematical models of heat-and-mass transfer and convection-diffusion processes. The coefficients and right-hand side of the system are recovered under certain additional overdetermination conditions, which are the integrals of a solution with weights over some collection of domains. We prove an existence and uniqueness theorem, as well as stability estimates. The results are local in time. The main functional spaces used are Sobolev spaces. These results serve as the base for justifying of the convergence of numerical algorithms for inverse problems with pointwise overdetermination, which arise, in particular, in the heatand-mass transfer problems on determining the source function or the parameters of a medium.

Keywords: parabolic system; convection-diffusion; heat-and-mass transfer; inverse problem; control problem; boundary value problem; well-posedness.

\section{Introduction}

We examine the question on recovering of the right-hand side and coefficients in a second order convection-diffusion system. Let $G$ be a domain in $\mathbb{R}^{n}$ with boundary $\Gamma$ of class $C^{2}$ and let $Q=G \times(0, T)$. This system is of the form

$$
u_{t}+A(t, x, D) u=f_{c},(t, x) \in Q,
$$

where $A$ is a second order elliptic operator with matrix coefficients of dimension $h \times h$. The equation (1) is supplemented with the initial and boundary conditions

$$
\left.u\right|_{t=0}=u_{0},\left.\quad u\right|_{S}=g(t, x),
$$

where $S=(0, T) \times \Gamma$. The right-hand side and the operator $A$ in (1) are of the form

$$
\begin{gathered}
f_{c}=\sum_{i=1}^{r_{0}} b_{i}(t, x) q_{i}(t)+f \\
A(t, x, D) u=A=\sum_{i=r_{0}+1}^{r} q_{i}(t) A_{i}(x, t)+A_{r+1}(x, t), A_{i} u=\sum_{|\alpha| \leq 2} a_{\alpha}^{i} D^{\alpha} u .
\end{gathered}
$$

The unknowns in (1), (2) are a solution $u$ and the functions $q_{i}(t)(i=1,2, \ldots, r)$ occurring into the right-hand side of (1) and the operator $A$. We consider the following overdetermination conditions:

$$
\int_{G_{i}} u \varphi_{i}(x) d x=\psi_{i}(t), i=1,2, \ldots, s, r=s h
$$


where $G_{i} \subset G$ are some domains. Consider also the overdetermination conditions

$$
u\left(x_{i}, t\right)=\psi_{i}(t), x_{i} \in G, i=1,2 \ldots, s, \quad r=s h .
$$

The problem of this type arise when describing heat and mass transfer, convectiondiffusion, and filtration processes (see [1-5]). Inverse problems on recovering of the coefficients of an equation (1), depending on $t$ with the overtermination conditions (5), where $r=1$ and $G_{i}=G$, are exposed in [6-12]. The linear inverse problems on recovering of the right-hand side are studied in $[5,13]$ respectively. Similarly, both types of problems with conditions (5) and (6) are examined in $[4,14]$ and $[15,16]$. A large number of physical statements and numerical methods of solving of the above-mentioned inverse problems with condition (6) is exposed in [27] and [28]. The problem on recovering of the source function (3) with the overdetermination conditions of the form (6) can be found in [29, Ch. 3], where the main attention is payed to numerical methods. In this monograph the problem of determination of the source function $G(x, t)$, with given measurements $(6)$ is examined. Here, the source function is replaced with its approximation of the form (3) which is calculated numerically. Note that most articles are devoted to the case of some model equations, where $n=1$. We can note only articles [17,18], where problems $(1),(2),(6)$ in general statement are treated. We can also refer to monographs $[2,6,14,19,20]$, where the reader can find statements of inverse problems for parabolic equations and systems and the corresponding existence and uniqueness theorems as well as some numerical methods for inverse problems solving.

In the present article under natural conditions on the data of the problem, we demonstrate that problem (1) - (5) is uniquely solvable and establish stability estimates for solutions. On one hand, problem (1) - (5) is of interest in its own right. On the other hand, a solution to problem (1) - (4), (6) can be approximated by solutions to the problem $(1)-(5)$ for a suitable choice of the weights $\varphi_{i}=\varphi_{i}(x, \varepsilon)$ depending on a parameter $\varepsilon>0$ (actually, we can construct an approximation of the Dirac $\delta$-function). The convergence can be established under appropriate conditions on the data. The latter fact allows to construct numerical algorithms for solving of problem (1) - (4), (6). We should note that most of the authors for numerical solution of the inverse problems use methods based on minimization of some functional (which is not convex) (see, for instance, [29] или [27]). Algorithms relying on an approximation of solutions to the problem $(1)-(4)$, (6) by solutions to the problem (1) - (5) allow to construct simpler methods and this fact is confirmed by numerical experiments. In the next section, we present some auxiliary statements and conditions on the data. In section 3 we state and prove our main results (Theorems 4,5 ).

\section{Definitions and Auxiliary Statements}

Let $E$ be a Banach space. The symbol $L_{p}(G ; E)\left(G\right.$ is a domain in $\left.\mathbb{R}^{n}\right)$ stands for the space of strongly measurable functions $u(x)$ defined on $G$ with values in $E$ such that the norm \|\|$u(x)\left\|_{E}\right\|_{L_{p}(G)}$ is finite [21]. We also use the spaces $C^{k}(\bar{G})$ comprising functions having derivatives up to the order $k$ inclusively in $G$ continuous in $G$ and admitting continuous extensions onto $\bar{G}$. The notations of the Sobolev spaces $W_{p}^{s}(G ; E), W_{p}^{s}(Q ; E)$ and so on are conventional (see [21,22]). If $E=\mathbb{C}$ or $E=\mathbb{C}^{n}$ then we use the notation $W_{p}^{s}(G)$ or $C^{k}(\bar{G})$ rather than $W_{p}^{s}(G ; E)$ or $C^{k}(\bar{G} ; E)$. Thus, the inclusion $u \in W_{p}^{s}(G)$ (or $\left.u \in C^{k}(\bar{G})\right)$ for a given vector-function $u=\left(u_{1}, u_{2}, \ldots, u_{k}\right)$ means that every component 
of $u_{i}$ belongs to $W_{p}^{s}(G)$ (or $C^{k}(\bar{G})$ ). In this case the norm of the vector-function is the sum of the norms of the coordinates. A similar convention is used for matrices as well. Given an interval $J=(0, T)$, assign $W_{p}^{s, r}(Q)=W_{p}^{s}\left(J ; L_{p}(G)\right) \cap L_{p}\left(J ; W_{p}^{r}(G)\right)$ and, respectively, $W_{p}^{s, r}(S)=W_{p}^{s}\left(J ; L_{p}(\Gamma)\right) \cap L_{p}\left(J ; W_{p}^{r}(\Gamma)\right)$. In what follows the symbol $\nabla u$ stands for the vector $\left(u_{x_{1}}, u_{x_{2}}, \ldots, u_{x_{n}}\right)$, i. e. the gradient of $u$ in the space variables. The condition $\Gamma \in C^{\alpha}(\alpha \geq 1)$ is understood conventionally (see [25]).

The smoothness and consistency conditions. Fix $p>n+2$. We assume that

$$
\begin{gathered}
u_{0}(x) \in W_{p}^{2-2 / p}(G), \quad g(x, t) \in W_{p}^{1-1 / 2 p, 2-1 / p}(S), \quad g(x, 0)=\left.u_{0}(x)\right|_{\partial G}, \\
\psi_{i}(t) \in C^{1}([0, T]), \psi_{i}(0)=\int_{G_{i}} u_{0}(x) \varphi_{i}(x) d x, i=1,2, \ldots, s, \\
a_{\alpha}^{i}(t, x) \in L_{\infty}(Q) \quad(|\alpha|<2), \quad a_{\alpha}^{i} \in C(\bar{Q})(|\alpha|=2) .
\end{gathered}
$$

We assume below that the boundaries of the domains $\left\{G_{j}\right\}(j=1,2, \ldots, s)$ those in $(5)$ belongs to the class $C^{1}$. We employ the following conditions on the weights $\left\{\varphi_{j}(x)\right\}$ :

$$
\begin{gathered}
\operatorname{supp} \varphi_{j} \subset \overline{G_{j}}, \quad \varphi_{j} \in W_{q}^{1}\left(G_{j}\right)\left(\frac{1}{q}+\frac{1}{p}=1\right), j=1,2, \ldots, s \\
\operatorname{supp} \varphi_{j} \subset G_{j}, \varphi_{j} \in L_{1}(G), j=1,2, \ldots, s .
\end{gathered}
$$

Let $G_{0}=\cup_{j=1}^{s} G_{j}, Q_{0}=G_{0} \times(0, T)$. Under the condition (10) we require that

$$
\begin{gathered}
b_{j}, f \in C\left([0, T] ; L_{p}\left(G_{0}\right)\right)\left(j=1,2, \ldots, r_{0}\right), a_{\alpha}^{i} \in C\left([0, T], W_{p}^{1}\left(G_{0}\right)\right) \text { for }|\alpha|=2, \\
a_{\alpha}^{i} \in C\left([0, T], L_{p}\left(G_{0}\right)\right) \quad\left(i=r_{0}+1, r_{0}+2, \ldots, r+1\right) \text { for }|\alpha| \leq 1 .
\end{gathered}
$$

If we replace (10) with (11) then we need the conditions

$$
\begin{gathered}
\nabla b_{k}, \nabla f \in L_{p}\left(Q_{0}\right), \quad \nabla u_{0} \in W_{p}^{2-\frac{2}{p}}\left(G_{0}\right), \nabla a_{\alpha}^{i}(x, t) \in L_{\infty}\left(Q_{0}\right)(|\alpha| \leq 2), \\
a_{\alpha}^{i} \in C\left([0, T], L_{\infty}\left(G_{0}\right)\right) \quad(|\alpha| \leq 1), b_{k}, f \in C\left([0, T] ; L_{\infty}\left(G_{0}\right)\right) \quad\left(k=1,2, \ldots, r_{0}\right),
\end{gathered}
$$

where $i=r_{0}+1, r_{0}+2, \ldots, r$. In the case of the problem (1)-(5) we define the matrix $B$ of dimension $r \times r$ whose rows with the numbers from $(k-1) h+1$ to $k h,(k=1,2, \ldots, s)$ are occupied by the $h \times r$-matrices with columns

$$
\int_{G} b_{1}(x, 0) \varphi_{k} d x, \ldots, \int_{G} b_{r_{0}}(x, 0) \varphi_{k} d x,-\int_{G} A_{r_{0}+1}(x, 0) u_{0} \varphi_{k} d x, \ldots,-\int_{G} A_{r}(x, 0) u_{0} \varphi_{k} d x
$$

We require that

$$
\operatorname{det} B \neq 0 \quad \forall t \in[0, T] \text {. }
$$

Assign $G_{\delta, i}=\left\{x \in G_{i}: \rho\left(x, \partial G_{i}\right)>\delta\right\}, Q_{\delta, i}^{\gamma}=G_{\delta, i} \times(0, \gamma), G_{\delta}=\cup_{i=1}^{s} G_{\delta, i}$, and $Q_{\delta}=$ $G_{\delta} \times(0, T), Q_{\delta}^{\gamma}=G_{\delta} \times(0, \gamma)(\delta \geq 0), Q^{\gamma}=G \times(0, \gamma)$. Let $A=\sum_{|\alpha| \leq 2} a_{\alpha} D^{\alpha}$, where $a_{\alpha}$ are $h \times h$-matrices. This expression can be also rewritten in the form $A=-\sum_{i, j=1}^{n} a_{i j} \partial_{x_{i} x_{j}}+$ $\sum_{i=1}^{n} a_{i} \partial_{x_{i}}+a_{0}$. We say that $A$ is elliptic whenever

$$
\operatorname{Re} \sum_{i, j=1}^{n}\left(a_{i j}(x, t) \xi^{i}, \xi^{j}\right) \geq \delta_{0} \sum_{i=1}^{n}\left|\xi^{i}\right|^{2}, \quad \forall \xi^{1}, \xi^{2}, \ldots, \xi^{n} \in \mathbb{R}^{h}, \forall(x, t) \in Q .
$$


Here $\delta_{0}$ is some positive constant. The following theorems are valid.

Theorem 1. Assume that $G$ is a bounded domain with boundary of class $C^{2}$, the conditions (7) hold, the coefficients of the operator $A=\sum_{|\alpha| \leq 2} a_{\alpha} D^{\alpha}$ satisfy the condition

$$
a_{\alpha}(t, x) \in L_{\infty}(Q)(|\alpha|<2), a_{\alpha} \in C(\bar{Q})(|\alpha|=2)
$$

and the ellipticity condition (17) holds. If $f \in L_{p}(Q)$ then there exists a unique solution $u \in W_{p}^{1,2}(Q)$ to the problem

$$
u_{t}+A\left(t, x, D_{x}\right) u=f,\left.\quad u\right|_{t=0}=u_{0}(x),\left.u\right|_{S}=g,
$$

satisfying the estimate

$$
\|u\|_{W_{p}^{1,2}(Q)} \leq c\left[\|f\|_{L_{p}(Q)}+\|g\|_{W_{p}^{1-1 / 2 p, 2-1 / p}(S)}+\left\|u_{0}\right\|_{W_{p}^{2-2 / p}(G)}\right],
$$

where $c$ is a constant independent of $f, u_{0}$ and a solution $u$. If we additionally assume that

$$
\nabla u_{0} \in W_{p}^{2-\frac{2}{p}}\left(G_{0}\right), \nabla a_{\alpha}(x, t) \in W_{\infty}^{1}\left(Q_{0}\right),|\alpha| \leq 2,
$$

and $\nabla f \in L_{p}\left(Q_{0}\right)$ then a solution $u$ possesses the property $\nabla u \in W_{p}^{1,2}\left(Q_{\delta}\right)$ for all $\delta>0$ and, for a fixed $\delta>0$, we have the estimate

$$
\begin{gathered}
\|\nabla u\|_{W_{p}^{1,2}\left(Q_{\delta}\right)}+\|u\|_{W_{p}^{1,2}(Q)} \leq c\left[\|f\|_{L_{p}(Q)}+\|\nabla f\|_{L_{p}\left(Q_{0}\right)}+\right. \\
\left.\|g\|_{W_{p}^{1-1 / 2 p, 2-1 / p}(S)}+\left\|u_{0}\right\|_{W_{p}^{2-2 / p}(G)}+\left\|\nabla u_{0}\right\|_{W_{p}^{2-2 / p}\left(G_{0}\right)}\right] .
\end{gathered}
$$

Proof. The first claim follows from Theorem 10.4 in [25]. The second claim is justified conventionally with the use of the finite difference method and Lemma 4.6 of Ch. 2 in [26].

Theorem 2. Assume that $G$ is a bounded domain with boundary of the class $C^{2}$, the coefficients of $A=\sum_{|\alpha| \leq 2} a_{\alpha} D^{\alpha}$ satisfy (18), the ellipticity condition (17) holds, and $f \in L_{p}\left(Q^{\gamma}\right)(\gamma \in(0, T])$. Then there exists a unique solution $u \in W_{p}^{1,2}\left(Q^{\gamma}\right)$ to the problem

$$
u_{t}+A\left(t, x, D_{x}\right) u=g,\left.\quad u\right|_{t=0}=0,\left.\quad u\right|_{S}=0,
$$

satisfying the estimate

$$
\|u\|_{W_{p}^{1,2}\left(Q^{\gamma}\right)} \leq c\|g\|_{L_{p}\left(Q^{\gamma}\right)}
$$

where $c$ is a constant independent of $\gamma$.

Proof. A solution sought agrees on $[0, \gamma]$ with a solution $u_{\gamma}$ to the problem (19) with the right-hand side $g_{\gamma}=\left\{\begin{array}{ll}g, & t \in[0, \gamma] \\ 0, & t \in(\gamma, T]\end{array} \in L_{p}(Q)\right.$ and the homogeneous initial and boundary conditions. Theorem 1 yields the estimate $\left\|u_{\gamma}\right\|_{W_{p}^{2,1}(Q)} \leq c\left\|g_{\gamma}\right\|_{L_{p}(Q)} \leq c\|g\|_{L_{p}\left(Q^{\gamma}\right)}$ which validates $(24)$.

Theorem 3. Assume that the conditions of Theorem 2 and condition (21) on $a_{\alpha}$ hold Then a solution $u$ to problem (23) for a fixed $\delta_{1}>0$ satisfies the estimate

$$
\|u\|_{W_{p}^{1,2}\left(Q^{\gamma}\right)}+\|\nabla u\|_{W_{p}^{1,2}\left(Q_{\delta_{1}}^{\gamma}\right)} \leq c\left(\|g\|_{L_{p}\left(Q^{\gamma}\right)}+\|\nabla g\|_{L_{p}\left(Q_{0}^{\gamma}\right)}\right),
$$

where $c$ is independent of $\gamma$.

Proof. The proof is in line with that of Theorem 2. 


\section{The Basic Results}

Define the constants $q_{i}^{0}(i=1,2, \ldots, r)$ as solutions to the system

$$
\psi_{j t}(0)+\sum_{i=r_{0}+1}^{r} q_{i}^{0} \int_{G} A_{i} u_{0} \varphi_{j} d x+\int_{G} A_{r+1} u_{0} \varphi_{j} d x=\sum_{i=1}^{r_{0}} q_{i}^{0} \int_{G} b_{i}(x, 0) \varphi_{j} d x+\int_{G} f \varphi_{j} d x
$$

where $j=1,2, \ldots, s$. In the following theorem we assume that

$$
\text { the operator } A^{0}=\sum_{i=r_{0}+1}^{r} q_{i}^{0} A_{i}+A_{r+1} \text { is elliptic. }
$$

Theorem 4. Let the conditions (7) - (8), (9), (10), (12) - (13), (16), (27) hold. Then there exists $\gamma_{0}>0$ such that, for $t \in\left[0, \gamma_{0}\right]$, there exists a unique solution $(u, \vec{q})\left(\vec{q}=\left(q_{1}, . ., q_{r}\right)\right)$ to the problem $(1)-(5)$ such that $u \in W_{p}^{1,2}\left(Q^{\gamma_{0}}\right), q_{i}(t) \in C\left(\left[0, \gamma_{0}\right]\right), i=1,2, \ldots, r$. A solution depends continuously on the data of the problem, $i$. e., for every two solutions $\left(u^{i}, q_{1}^{i}, \ldots, q_{r}^{i}\right)(i=1,2)$ to the problem $(1)-(5)$ from the class

$$
u^{i} \in W_{p}^{1,2}\left(Q^{\gamma_{0}}\right), q_{j}^{i} \in C\left(\left[0, \gamma_{0}\right]\right),(i=1,2, j=1,2, \ldots, r),
$$

corresponding two different collections of the data $f^{i}, \psi_{j}^{i}, u_{0}^{i}, g^{i}(j=1,2, \ldots, s, i=1,2)$ satisfying (7) - (8), (9) - (10), (12) - (13) and such that the condition (16) holds and

$$
\begin{gathered}
\left\|f^{i}\right\|_{L_{p}(Q)}+\sum_{j=1}^{s}\left\|\psi_{j}^{i}\right\|_{C^{1}([0, T])}+\left\|f^{i}\right\|_{C\left([0, T] ; L_{p}\left(G_{0}\right)\right)}+ \\
+\left\|u_{0}^{i}\right\|_{W_{p}^{2-2 / p}(G)}+\left\|g^{i}\right\|_{W_{p}^{1-1 / 2 p, 2-1 / p}(S)} \leq R, \quad(i=1,2,)
\end{gathered}
$$

there exists $\gamma_{1}=\gamma_{1}(R)$ such that the stability estimate

$$
\begin{gathered}
\left\|u^{1}-u^{2}\right\|_{W_{p}^{1,2}\left(Q^{\left.\gamma_{1}\right)}\right.}+\sum_{j=1}^{r}\left\|q_{j}^{1}-q_{j}^{2}\right\|_{C\left(\left[0, \gamma_{1}\right]\right)} \leq C\left(\left\|f^{1}-f^{2}\right\|_{L_{p}\left(Q^{\gamma_{1}}\right)}+\sum_{j=1}^{r}\left\|\psi_{j}^{1}-\psi_{j}^{2}\right\|_{C^{1}\left(\left[0, \gamma_{1}\right]\right)}+\right. \\
\left.+\left\|f^{1}-f^{2}\right\|_{C\left([0, T] ; L_{p}\left(G_{0}\right)\right)}+\left\|u_{0}^{1}-u_{0}^{2}\right\|_{W_{p}^{2-2 / p}(G)}+\left\|g^{1}-g^{2}\right\|_{W_{p}^{1-1 / 2 p, 2-1 / p}\left(S^{\gamma_{1}}\right)}\right),
\end{gathered}
$$

is valid, where $C$ is a constant independent of $R$ and $\gamma_{1}$ and $S^{\gamma_{1}}=\partial G \times\left(0, \gamma_{1}\right)$.

Proof. We construct a function $\Phi$ as a solution to the problem

$$
\Phi_{t}+\left(\sum_{i=r_{0}+1}^{r} q_{i}^{0} A_{i}+A_{r+1}\right) \Phi=f+\sum_{i=1}^{r_{0}} q_{i}^{0} b_{i}(x, t),\left.\Phi\right|_{t=0}=u_{0}(x),\left.\Phi\right|_{S}=g .
$$

A solution to this problem exists and possesses the properties those of Theorem 1. Make the change $V=u-\Phi$ and $\vec{q}=\overrightarrow{q^{1}}+\overrightarrow{q^{0}}\left(\overrightarrow{q^{i}}=\left(q_{1}^{i}, \ldots, q_{r}^{i}\right), i=0,1\right)$. In this case $V$ is a solution to the problem

$$
V_{t}+A^{0} V+\sum_{i=r_{0}+1}^{r} q_{i}^{1} A_{i} V=\sum_{i=1}^{r_{0}} b_{i} q_{i}^{1}-\sum_{i=r_{0}+1}^{r} q_{i}^{1} A_{i} \Phi,\left.\quad V\right|_{t=0}=0,\left.V\right|_{S}=0 .
$$

Theorem 2 implies that for every $f \in L_{p}\left(Q^{\tau}\right)$ the problem

$$
V_{t}+A^{0} V=f,\left.V\right|_{t=0}=0,\left.V\right|_{S}=0
$$


is uniquely solvable and

$$
\|V\|_{W_{p}^{1,2}\left(Q^{\tau}\right)} \leq c\|g\|_{L_{p}\left(Q^{\tau}\right)}
$$

where the constant $c$ is independent of $\tau \in[0, T]$. Examine an auxiliary problem

$$
V_{t}+A^{0} V+\sum_{i=r_{0}+1}^{r} q_{i}^{1} A_{i} V=g(x, t),\left.\quad V\right|_{t=0}=0,\left.V\right|_{S}=0 .
$$

Let $\overrightarrow{q^{1}} \in B_{\mu, \tau}=\left\{\overrightarrow{q^{1}} \in C([0, \tau]):\left\|\overrightarrow{q^{1}}\right\|_{C([0, \tau])} \leq \mu\right\}(\tau \leq T)$. By Theorem 2, we have

$$
V+\left(\partial_{t}+A^{0}\right)^{-1} \sum_{i=r_{0}+1}^{r} q_{i}^{1} A_{i} V=\left(\partial_{t}+A^{0}\right)^{-1} g(x, t) .
$$

The estimate (31) yields

$$
\begin{gathered}
\left\|\left(\partial_{t}+A^{0}\right)^{-1} \sum_{i=r_{0}+1}^{r} q_{i}^{1} A_{i} V\right\|_{W_{p}^{1,2}\left(Q^{\tau}\right)} \leq c\left\|\sum_{i=r_{0}+1}^{r} q_{i}^{1} A_{i} V\right\|_{L_{p}\left(Q^{\tau}\right)} \leq \\
\left\|\overrightarrow{q^{1}}\right\|_{C([0, \tau])} c c_{1}\|V\|_{W_{p}^{1,2}\left(Q^{\tau}\right)} \leq \mu c c_{1}\|V\|_{W_{p}^{1,2}\left(Q^{\tau}\right)^{\tau}} .
\end{gathered}
$$

In what follows, we assume that $\mu \leq \mu_{0}=\frac{1}{2 c c_{1}}$. In this case we infer

$$
\left\|\left(\partial_{t}+A^{0}\right)^{-1}\left(\sum_{i=r_{0}+1}^{r} q_{i}^{1} A_{i} V\right)\right\|_{W_{p}^{1,2}\left(Q^{\tau}\right)} \leq \frac{1}{2}\|V\|_{W_{p}^{1,2}\left(Q^{\tau}\right)}
$$

and thereby (33) is uniquely solvable and a solution $V \in W_{p}^{1,2}(Q)$ satisfies the estimate

$$
\|V\|_{W_{p}^{1,2}\left(Q^{\tau}\right)} \leq 2\left\|\left(\partial_{t}+A^{0}\right)^{-1} g\right\|_{W_{p}^{1,2}\left(Q^{\tau}\right)} \leq 2 c\|g\|_{L_{p}\left(Q^{\tau}\right)}, \forall \overrightarrow{q^{1}} \in B_{\mu, \tau}
$$

Integrating equation (29) with the weight $\varphi_{i}$ over $G$, we obtain

$$
\begin{gathered}
\int_{G} V_{t} \varphi_{i} d x=\frac{\partial}{\partial t} \int_{G} V \varphi_{i} d x=\tilde{\psi}_{i t}(t), \quad \tilde{\psi}_{i}(t)=\psi_{i}-\int_{G} \Phi \varphi_{i} d x \\
\tilde{\psi}_{i t}+\int_{G} A^{0} V \varphi_{i} d x+\sum_{j=r_{0}+1}^{r} q_{j}^{1} \int_{G} A_{j} V \varphi_{i} d x=\sum_{j=1}^{r_{0}} q_{j}^{1} \int_{G} b_{j} \varphi_{i} d x-\sum_{j=r_{0}+1}^{r} q_{j}^{1} \int_{G} A_{j} \Phi \varphi_{i} d x
\end{gathered}
$$

where $i=1,2, \ldots, s$. Examine the matrix $B(t)$ of dimension $r \times r$ whose rows with the numbers from $(k-1) h+1$ to $k h,(k=1,2, \ldots, s)$ are occupied by the $h \times r$-matrices with the columns

$$
\int_{G} b_{1} \varphi_{k} d x, \ldots, \int_{G} b_{r_{0}} \varphi_{k} d x,-\int_{G} A_{r_{0}+1} \Phi \varphi_{k} d x, \ldots,-\int_{G} A_{r} \Phi \varphi_{k} d x .
$$

Note that $B(0)=B$ with the matrix $B$ that was defined before (16). Demonstrate that the entries of $B(t)$ are continuous in $t$. The continuity of the entries from the first $r_{0}$ columns results from (9). Consider the last $r-r_{0}$ columns. Since $\Phi \in W_{p}^{1,2}(Q)$, the embedding theorems yield

$$
\Phi \in C\left([0, T] ; W_{p}^{\alpha}(G)\right), \quad \alpha \leq 2(1-1 / p)
$$


The latter results, for example, from Theorem 1.8.3 in [21], where the Banach spaces $A_{0}, A_{1}$ are replaced with $W_{p}^{2}(G)$ and $L_{p}(G)$. In view of our conditions on $p, 2(1-1 / p)>n / p+1$ and, in particular, $W_{p}^{2(1-1 / p)}(G) \subset C^{\beta}(\bar{G})$ with $\beta \leq 2-2 / p-n / p$ [21]. Thus,

$$
W_{p}^{1,2}(Q) \subset C\left([0, T] ; W_{p}^{2\left(1-\frac{1}{p}\right)}(G)\right) \subset C\left([0, T] ; C^{\beta}(\bar{G})\right) \quad \beta \leq 2-\frac{2}{p}-\frac{n}{p} .
$$

In particular, changing $\Phi$ on a set of a zero measure if necessary, we can assume that the functions $D_{x}^{\alpha} \Phi$ for $|\alpha| \leq 1$ are continuous. We have $A_{j} \Phi=A_{j 0} \Phi+A_{j 1} \Phi\left(j>r_{0}\right.$, where $A_{j 0} \Phi=\sum_{|\alpha|=2} a_{\alpha}^{j} D^{\alpha} \Phi$ and $A_{j 1} \Phi=\sum_{|\alpha|<2} a_{\alpha}^{j} D^{\alpha} \Phi$. In view of (13) and the above-pointed properties of $\Phi$, for $|\alpha| \leq 1$ the functions $\int_{G} a_{\alpha}^{j} D^{\alpha} \Phi \varphi_{i} d x$ are continuous in $t$. Consider the case of $|\alpha|=2$. We conclude that

$$
\int_{G} a_{\alpha}^{j}(x, t) D^{\alpha} \Phi \varphi_{i} d x d t=\int_{\Gamma_{i}} a_{\alpha}(x, t) D^{\alpha^{\prime}} \Phi \varphi_{i} n_{k} d \Gamma-\int_{G_{i}}\left(a_{\alpha} \varphi_{i}\right)_{x_{k}} D^{\alpha^{\prime}} \Phi d x
$$

where $D^{\alpha} \Phi=\frac{\partial}{\partial x_{k}} D^{\alpha^{\prime}} \Phi, n_{k}$ is a coordinate of the unit outward normal to $\Gamma_{i}=\partial G_{i}$. By the same reasons, the obtained integrals are continuous in $t$.

In view of continuity of the entries of $B(t)$, there exists $\tau_{0}>0$ and a constant $\tilde{\delta}>0$ such that $|\operatorname{det} B(t)|>\tilde{\delta}, \forall t \in\left[0, \tau_{0}\right]$. The equalities (36) can be rewritten as

$$
B(t) \overrightarrow{q^{1}}=\left[\begin{array}{c}
\tilde{\psi}_{1 t}+\left(A^{0} V, \varphi_{1}\right)+\sum_{i=r_{0}+1}^{r} q_{i}^{1}\left(A_{i} V, \varphi_{1}\right) \\
\vdots \\
\tilde{\psi}_{s t}+\left(A^{0} V, \varphi_{s}\right)+\sum_{i=r_{0}+1}^{r} q_{i}^{1}\left(A_{i} V, \varphi_{s}\right)
\end{array}\right],(u, v)=\int_{G} u \bar{v} d G
$$

Thus,

$$
\overrightarrow{q^{1}}=g_{0}+R\left(\overrightarrow{q^{1}}\right)
$$

where $g_{0}=B(t)^{-1}\left[\begin{array}{c}\tilde{\psi}_{1 t} \\ \vdots \\ \tilde{\psi}_{s t}\end{array}\right], R\left(\overrightarrow{q^{1}}\right)=B(t)^{-1}\left[\begin{array}{c}\left(A^{0} V, \varphi_{1}\right)+\sum_{i=r_{0}+1}^{r} q_{i}^{1}\left(A_{i} V, \varphi_{1}\right) \\ \vdots \\ \left(A^{0} V, \varphi_{s}\right)+\sum_{i=r_{0}+1}^{r} q_{i}^{1}\left(A_{i} V, \varphi_{s}\right)\end{array}\right]$ and $V$ is a solution to the problem (29), which exists whenever $\vec{q}^{1} \in B_{\mu, \tau}$, with $\mu \leq \mu_{0}$ и $\tau \leq T$. Consider the vector

$$
g_{0}=B(t)^{-1}\left[\begin{array}{c}
\tilde{\psi}_{1 t} \\
\vdots \\
\tilde{\psi}_{s t}
\end{array}\right]
$$

Let $\tau \leq \tau_{0}$. We have $\left\|g_{0}\right\|_{C([0, \tau])} \leq c \max _{1 \leq i \leq s}\left\|\tilde{\psi}_{i t}\right\|_{C([0, \tau])}$. In view of $(26), \tilde{\psi}_{i t}(0)=0$. By continuity of $\tilde{\psi}_{i t}, \exists \tau_{1} \leq \tau_{0}:\left\|g_{0}\right\|_{C([0, \tau])} \leq \frac{\mu_{0}}{2}, \forall \tau_{0} \leq \tau_{1}$. Show that there exists $\tau_{2} \leq \tau_{1}$ such that the equation (39) is uniquely solvable in the ball $B_{\mu_{0}, \tau_{2}}=\left\{\overrightarrow{q^{1}}:\left\|\overrightarrow{q^{1}}\right\|_{C\left(\left[0, \tau_{2}\right]\right)} \leq \mu_{0}\right\}$. Derive estimates for the operator $R\left(\overrightarrow{q^{1}}\right)$. Let $\overrightarrow{q^{1}}, \overrightarrow{q^{2}} \in B_{\mu_{0}, \tau}, \quad\left(\tau \leq \tau_{1}\right)$, and $V^{1}, V^{2}$ are 
solutions to problem (29) (with $\overrightarrow{q^{1}}$ and $\overrightarrow{q^{2}}$ on the right-hand side) satisfying the initial and boundary conditions $\left.V^{j}\right|_{t=0}=0,\left.V^{j}\right|_{S}=0(j=1,2)$. We have

$$
V_{t}^{j}+A^{0} V^{j}+\sum_{j=r_{0}+1}^{r} q_{i}^{j} A_{i} V^{j}=\sum_{i=1}^{r_{0}} q_{i}^{j} b_{i}-\sum_{i=r_{0}+1}^{r} q_{i}^{j} A_{i} \Phi,\left.V^{j}\right|_{t=0}=0,\left.V^{j}\right|_{S}=0
$$

where $i=1,2, \ldots, m, j=1,2$. Estimate $\left\|R\left(\overrightarrow{q^{1}}\right)-R\left(\overrightarrow{q^{2}}\right)\right\|_{C([0, \tau])}$. We obtain

$$
\begin{gathered}
\left\|R\left(\overrightarrow{q^{1}}\right)-R\left(\overrightarrow{q^{2}}\right)\right\|_{C([0, \tau])} \leq c \max _{1 \leq j \leq s} \|\left(A^{0}\left(V^{1}-V^{2}\right), \varphi_{j}\right)+ \\
\sum_{i=r_{0}+1}^{r}\left(q_{i}^{1}\left(A_{i} V^{1}, \varphi_{j}\right)-q_{i}^{2}\left(A_{i} V^{2}, \varphi_{j}\right)\right) \|_{C([0, \tau])} .
\end{gathered}
$$

Subtracting the equations (40) for $j=1,2$, we arrive at the equality

$$
\begin{aligned}
& \left(V^{1}-V^{2}\right)_{t}+A^{0}\left(V^{1}-V^{2}\right)+\sum_{i=r_{0}+1}^{r} q_{i}^{2}\left(A_{i} V^{1}-A_{i} V^{2}\right)= \\
& \sum_{i=1}^{r_{0}}\left(q_{i}^{1}-q_{i}^{2}\right) b_{i}-\sum_{i=r_{0}+1}^{r}\left(q_{i}^{1}-q_{i}^{2}\right) A_{i} V^{1}-\sum_{i=1}^{r_{0}}\left(q_{i}^{1}-q_{i}^{2}\right) A_{i} \Phi .
\end{aligned}
$$

Note that in view of (35) the functions $V^{j}$ meet the estimate

$$
\left\|V^{j}\right\|_{W_{p}^{1,2}\left(Q^{\tau}\right)} \leq 2 C\left\|\sum_{i=1}^{r_{0}} q_{i}^{j} b_{i}-\sum_{i=r_{0}+1}^{r} q_{i}^{j} A_{i} \Phi\right\|_{L_{p}\left(Q^{\tau}\right)} \leq C_{1}\left\|\overrightarrow{q^{j}}\right\|_{C([0, \tau])} \leq C_{1} \mu_{0}
$$

where $C_{1}$ is independent of $x$ and $\tau$. Estimate (35) and equalities (42) yield

$$
\begin{gathered}
\left\|V^{1}-V^{2}\right\|_{W_{p}^{1,2}\left(Q^{\tau}\right)} \leq C_{2}\left\|\overrightarrow{q^{1}}-\overrightarrow{q^{2}}\right\|_{C([0, \tau])}+\max _{i}\left\|A_{i} V^{1}\right\|_{L_{p}\left(Q^{\tau}\right)} C_{3}\left\|\overrightarrow{q^{1}}-\overrightarrow{q^{2}}\right\|_{C([0, \tau])} \leq \\
\left\|\overrightarrow{q^{1}}-\overrightarrow{q^{2}}\right\|_{C([0, \tau])}\left(C_{2}+C_{3}\left\|V^{1}\right\|_{W_{p}^{1,2}\left(Q^{\tau}\right)}\right) \leq\left\|\overrightarrow{q^{1}}-\overrightarrow{q^{2}}\right\|_{C([0, \tau])}\left(C_{2}+C_{3} C_{1} \mu_{0}\right) .
\end{gathered}
$$

Estimate the right-hand side of (41) using the inclusion $\varphi_{j} \in W_{q}^{1}\left(G_{j}\right)$. Consider $\left|\left(A^{0} v, \varphi_{j}\right)\right|$ for $v=V^{1}-V^{2}$. We have $A^{0} v=A_{0} v+A_{1} v$, where $A_{0} v \stackrel{q}{=} \sum_{|\alpha|=2} a_{\alpha} D^{\alpha} v$ and $A_{1} v=$ $\sum_{|\alpha|<2} a_{\alpha} D^{\alpha} v$. For $|\alpha| \leq 1$, we infer $\left|\int_{G} a_{\alpha} D^{\alpha} v \varphi_{i} d x\right| \leq c\left\|D^{\alpha} v\right\|_{L_{\infty}\left(G_{0}\right)} \leq c\|v\|_{W_{\infty}^{1}\left(G_{0}\right)}$. Thus,

$$
\left|\int_{G} A_{1} v \varphi_{i} d x\right| \leq c_{1}\|v\|_{W_{\infty}^{1}(G)}
$$

Consider the expression $\int_{G} A_{0} v \varphi_{i} d x$. It contains the summands

$$
\int_{G} a_{\alpha}(x, t) D^{\alpha} v \varphi_{i} d x d t=\int_{\Gamma_{i}} a_{\alpha}(x, t) D^{\alpha^{\prime}} v \varphi_{i} n_{k} d \Gamma-\int_{G_{i}}\left(a_{\alpha} \varphi_{i}\right)_{x_{k}} D^{\alpha^{\prime}} v d x,
$$

where $D^{\alpha} v=\frac{\partial}{\partial x_{k}} D^{\alpha^{\prime}} v, n_{k}$ is the $k$-th coordinate of the unit normal to $\Gamma_{i}=\partial G_{i}$. The second integral is estimated as

$$
\int_{G_{i}}\left|a_{\alpha}\right|\left|D^{\alpha^{\prime}} v\right| \cdot\left|\varphi_{i x_{k}}\right| d x+\int_{G_{0}}\left|a_{\alpha x_{k}}\right| \cdot\left|D^{\alpha^{\prime}} v\right| \cdot\left|\varphi_{i}\right| d x \leq
$$




$$
\leq M\left\|D^{\alpha^{\prime}} v\right\|_{L_{\infty}\left(G_{0}\right)}\left(\int_{G_{i}}\left|\varphi_{i x_{k}}\right|^{q} d x\right)^{\frac{1}{q}}+M_{1}\left\|D^{\alpha^{\prime}} v\right\|_{L_{\infty}\left(G_{0}\right)}\left(\int_{G_{i}} \varphi_{i}^{q} d x\right)^{\frac{1}{q}} .
$$

Therefore, the second integral is estimates by $c_{1}\|v\|_{W_{\infty}^{1}(G)}$. Estimate the first integral with the use of the trace theorems (see, for instance, $[21,25,26]$ ). In view of (38) we can assume that $v \in C\left([0, T] ; C^{1}(\bar{G})\right)$, and thus $a_{\alpha} \in C\left(\overline{Q_{0}}\right)$ and

$$
\left|\int_{\Gamma_{i}} a_{\alpha} D^{\alpha^{\prime}} v \varphi_{i} n_{k} d \Gamma\right| \leq\|v\|_{W_{\infty}^{1}(G)}\left\|a_{\alpha}\right\|_{L_{\infty}\left(G_{0}\right)}\left\|\varphi_{i}\right\|_{L_{q}\left(\Gamma_{i}\right)} \leq c_{2}\|v\|_{W_{\infty}^{1}(G)} .
$$

We involved the fact that $\varphi_{i} \in W_{q}^{1-1 / q}\left(\Gamma_{i}\right)$ due to embedding theorems. These two inequalities ensure that there exists $c_{3}$ such that

$$
\left|\int_{G} A_{0} v \varphi_{i} d x\right| \leq c_{3}\|v\|_{W_{\infty}^{1}(G)} .
$$

By the embedding theorems and the interpolation inequalities (see (38), [21]), we infer

$$
\|v\|_{W_{\infty}^{1}(G)} \leq c_{4}\|v\|_{W_{p}^{1+\frac{n}{p}}(G)} \leq c_{5}\|v\|_{W_{p}^{2-\frac{2}{p}}(G)}^{\theta}\|v\|_{L_{p}(G)}^{1-\theta}, \quad \theta\left(2-\frac{2}{p}\right)=1+\frac{n}{p} .
$$

In this case relations (45), (46), (47) imply that

$$
\max _{1 \leq j \leq s}\left\|\left(A^{0}\left(V^{1}-V^{2}\right), \varphi_{j}\right)\right\|_{C([0, \tau])} \leq C_{6}\|v\|_{C\left([0, \tau] ; W_{p}^{2-\frac{2}{p}}(G)\right)}^{\theta}\|v\|_{C\left([0, \tau] ; L_{p}(G)\right)}^{1-\theta} .
$$

As it was noted, $v \in C\left([0, \tau] ; W_{p}^{2-2 / p}(G)\right)$ after a possible modification on a set of zero measure. Next, $v=\int_{0}^{t} v_{\tau}(x, \tau) d \tau$ and thereby

$$
\|v\|_{C\left([0, \tau] ; L_{p}(G)\right)} \leq \tau^{\frac{1}{q}}\left\|v_{t}\right\|_{L_{p}\left([0, \tau] ; L_{p}(G)\right)}, \quad(1 / p+1 / q=1) .
$$

Therefore, $\left\|\left(A v, \varphi_{j}\right)\right\|_{C([0, \tau])} \leq C \tau^{\frac{1-\theta}{q}}\|v\|_{W_{p}^{1,2}\left(Q^{\tau}\right)}$. In this case we have

$$
\left\|\left(A^{0}\left(V^{1}-V^{2}\right), \varphi_{j}\right)\right\|_{C([0, \tau])} \leq c_{7} \tau^{\frac{1-\theta}{q}}\left\|V^{1}-V^{2}\right\|_{W_{p}^{1,2}\left(Q^{\tau}\right)},
$$

where $C_{1}$ is independent of $\tau$. Using (44), we obtain

$$
\left\|\left(A^{0}\left(V^{1}-V^{2}\right), \varphi_{j}\right)\right\|_{C([0, \tau])} \leq c_{8} \tau^{\frac{1-\theta}{q}}\left\|\overrightarrow{q^{1}}-\overrightarrow{q^{2}}\right\|_{C([0, \tau])},
$$

Consider the second summand in (41). We have

$$
\begin{gathered}
\sum_{i=r_{0}+1}^{r}\left(q_{i}^{1}\left(A_{i} V^{1}, \varphi_{j}\right)-q_{i}^{2}\left(A_{i} V^{2}, \varphi_{j}\right)\right)= \\
\sum_{i=r_{0}+1}^{r}\left(q_{i}^{1}-q_{i}^{2}\right)\left(A_{i} V^{1}, \varphi_{j}\right)+\sum_{i=r_{0}+1}^{r} q_{i}^{2}\left(A_{i} V^{1}-A_{i} V^{2}, \varphi_{j}\right) .
\end{gathered}
$$

The summands $\left(A_{i} V^{1}, \varphi_{j}\right),\left(A_{i}\left(V^{1}-V^{2}\right), \varphi_{j}\right)$ are estimated as the expression $\left(A^{0}\left(V^{1}-\right.\right.$ $\left.\left.V^{2}\right), \varphi_{j}\right)($ see $(50))$. We have

$$
\begin{gathered}
\left\|\sum_{i=r_{0}+1}^{r}\left(q_{i}^{1}-q_{i}^{2}\right)\left(A_{i} V^{1}, \varphi_{j}\right)\right\|_{C[0, \tau]} \leq\left\|\overrightarrow{q^{1}}-\overrightarrow{q^{2}}\right\|_{C[0, \tau]} \tau^{\frac{1-\theta}{q}} c_{9}\left\|V^{1}\right\|_{W_{p}^{1,2}\left(Q^{\tau}\right)} \leq \\
\tau^{\frac{1-\theta}{q}} C\left(\mu_{0}\right)\left\|\overrightarrow{q^{1}}-\overrightarrow{q^{2}}\right\|_{C([0, \tau])} .
\end{gathered}
$$


Similarly, in view of (44), we infer

$$
\left\|\sum_{i=r_{0}+1}^{r} q_{i}^{2}\left(A_{i}\left(V^{1}-V^{2}\right), \varphi_{j}\right)\right\|_{C[0, \tau]} \leq c_{10} \tau^{\frac{1-\theta}{q}}\left\|\overrightarrow{q^{1}}-\overrightarrow{q^{2}}\right\|_{C([0, \tau])} .
$$

Relations (51) - (53) imply that

$$
\left\|R\left(\overrightarrow{q^{1}}\right)-R\left(\overrightarrow{q^{2}}\right)\right\|_{C[0, \tau]} \leq c_{11} \tau^{\frac{1-\theta}{q}}\left\|\overrightarrow{q^{1}}-\overrightarrow{q^{2}}\right\|_{C([0, \tau])}, \quad \forall q^{i} \in B_{\mu_{0}, \tau} .
$$

Find $\tau_{2} \leq \tau_{1}$ such that $c_{11} \tau_{2}^{\frac{1-\theta}{q}} \leq \frac{1}{2}$. In this case

$$
\left\|R\left(\overrightarrow{q^{1}}\right)-R\left(\overrightarrow{q^{2}}\right)\right\|_{C\left(\left[0, \tau_{2}\right]\right)} \leq \frac{1}{2}\left\|\overrightarrow{q^{1}}-\overrightarrow{q^{2}}\right\|_{C\left(\left[0, \tau_{2}\right]\right)}
$$

Since $R\left(\overrightarrow{q^{2}}\right)=0$ for $\overrightarrow{q^{2}}=0$, we have

$$
\left\|R\left(\overrightarrow{q^{1}}\right)\right\|_{C\left(\left[0, \tau_{2}\right]\right)} \leq \frac{1}{2}\left\|\overrightarrow{q^{1}}\right\|_{C\left(\left[0, \tau_{2}\right]\right)} .
$$

In this case the operator $R_{0}\left(\overrightarrow{q^{1}}\right)=g_{0}+R\left(\overrightarrow{q^{1}}\right)$ is contractive and takes the ball $B_{\mu_{0}, \tau_{2}}$ into itself. Indeed,

$$
\left\|R_{0}(q)\right\|_{C\left(\left[0, \tau_{2}\right]\right)} \leq\left\|g_{0}\right\|_{C\left(\left[0, \tau_{2}\right]\right)}+\left\|R\left(\overrightarrow{q^{1}}\right)\right\|_{C\left(\left[0, \tau_{2}\right]\right)} \leq \frac{\mu_{0}}{2}+\frac{\mu_{0}}{2}=\mu_{0}
$$

The fixed point theorem implies the existence of a solution $\overrightarrow{q^{1}}$ to equation (39) in this ball. By construction, $V$ is a solution to problem (29). Assign $\gamma_{0}=\tau_{2}$. Demonstrate that $V$ satisfies the conditions $\int_{G} V \varphi_{j} d x=\tilde{\psi}_{i}(t)$. Integrate equation (29) over $G$ with the weight $\varphi_{i}$. We have

$$
\frac{\partial}{\partial t} \int_{G} \varphi_{i} V d x+\int_{G} A^{0} V \varphi_{i} d x+\sum_{j=r_{0}+1}^{r} q_{j}^{1} \int_{G} A_{j} V \varphi_{i} d x=\sum_{j=1}^{r_{0}} q_{j}^{1} \int_{G} b_{j} \varphi_{i} d x-\sum_{j=r_{0}+1}^{r} q_{j}^{1} \int_{G} A_{j} \Phi \varphi_{i} d x .
$$

The function $q_{j}$ satisfies (36); subtracting the $i$-th equation from the previous equality, we obtain that $\left(\int_{G} \varphi_{i} v d x-\tilde{\psi}_{i}\right)_{t}=0$ or $\int_{G} \varphi_{i} v d x-\tilde{\psi}_{i}=\left.\left(\int_{G} \varphi_{i} v d x-\tilde{\psi}_{i}\right)\right|_{t=0}=0$ in view of the consistency conditions. Thus, $v$ is a solution to our problem. The stability estimate from the statement of the theorem was actually obtained in the proof and we omit the arguments.

Theorem 5. Let conditions (7) - (9), (11), (14) - (16), (27) hold. Then there exists $\gamma_{0}>0$ such that on the segment $\left[0, \gamma_{0}\right]$ there exists a unique solution $\left(u, q_{1}, . ., q_{r}\right)$ to problem $(1)$ - (5) such that

$$
u \in W_{p}^{1,2}\left(Q^{\gamma_{0}}\right), q_{i}(t) \in C\left(\left[0, \gamma_{0}\right]\right), i=1,2, \ldots, r .
$$

A solution continuously depends on the data of the problem, $i$. e., for a fixed $\delta_{1}>0$ and every two solutions $\left(u^{i}, q_{1}^{i}, \ldots, q_{r}^{i}\right)(i=1,2)$ to the problem $(1)-(5)$ of the class

$$
u^{i} \in W_{p}^{1,2}\left(Q^{\gamma_{0}}\right), q_{j}^{i} \in C\left(\left[0, \gamma_{0}\right]\right),(i=1,2, j=1,2, \ldots, r)
$$


corresponding two different collections of the data $f^{i}, \psi_{j}^{i}, u_{0}^{i}, g^{i}(j=1,2, \ldots, s, i=1,2)$ such that conditions (7) - (9), (11), (14) - (16), (27), (16) hold and

$$
\begin{gathered}
\left\|f^{i}\right\|_{L_{p}(Q)}+\sum_{j=1}^{s}\left\|\psi_{j}^{i}\right\|_{C^{1}([0, T])}+\left\|f^{i}\right\|_{C\left([0, T] ; L_{\infty}\left(G_{0}\right)\right)}+\left\|\nabla f^{i}\right\|_{L_{p}\left(Q_{0}\right)} \\
\left\|u_{0}^{i}\right\|_{W_{p}^{2-2 / p}(G)}+\left\|\nabla u_{0}^{i}\right\|_{W_{p}^{2-2 / p}(G)}+\left\|g^{i}\right\|_{W_{p}^{1-1 / 2 p, 2-1 / p}(S)} \leq R, \quad i=1,2,
\end{gathered}
$$

there exists a constant $\gamma_{1}=\gamma_{1}(R)$ such that the stability estimate

$$
\begin{gathered}
\left\|u^{1}-u^{2}\right\|_{W_{p}^{1,2}\left(Q^{\gamma_{1}}\right)}+\left\|\nabla\left(u^{1}-u^{2}\right)\right\|_{W_{p}^{1,2}\left(Q_{\delta_{1}}^{\gamma_{1}}\right)}+\sum_{j=1}^{r}\left\|q_{j}^{1}-q_{j}^{2}\right\|_{C\left(\left[0, \gamma_{1}\right]\right)} \leq \\
C\left(\left\|f^{1}-f^{2}\right\|_{L_{p}\left(Q^{\gamma_{1}}\right)}+\sum_{j=1}^{r}\left\|\psi_{j}^{1}-\psi_{j}^{2}\right\|_{C^{1}\left(\left[0, \gamma_{1}\right]\right)}+\left\|f^{1}-f^{2}\right\|_{C\left([0, T] ; L_{\infty}\left(G_{0}\right)\right)}+\right. \\
\left\|\nabla\left(f^{1}-f^{2}\right)\right\|_{L_{p}\left(Q_{0}\right)}+\left\|u_{0}^{1}-u_{0}^{2}\right\|_{W_{p}^{2-2 / p}(G)}+ \\
\left\|\nabla\left(u_{0}^{1}-u_{0}^{2}\right)\right\|_{W_{p}^{2-2 / p}\left(G_{0}\right)}+\left\|g^{1}-g^{2}\right\|_{W_{p}^{1-1 / 2 p, 2-1 / p}\left(S_{1}^{\gamma_{1}}\right)},
\end{gathered}
$$

holds, where $S^{\gamma_{1}}=\partial G \times\left(0, \gamma_{1}\right)$ and the constant $C$ is independent of $R$ and $\gamma_{1}$.

Proof. The proof relies on the same scheme as that of the proof of the previous theorem. As before, the claim is reduced to the solvability of equation (39).

The authors were supported by the Russian Foundation for Basic Research (Grant 12-0100260a).

\section{References}

1. Alekseev G.V. Optimizatsiya $v$ statsionarnykh zadachakh teplomassoperenosa $i$ magnitnoy gidrodinamiki [Optimization in Stationary Problems of Heat and Mass Transfer and Magnetic Hydrodynamics]. Moscow, Nauchnyi Mir, 2010.

2. Belov Ya.Ya. Inverse Problems for Parabolic Equations. Utrecht, VSP, 2002.

3. Babeshko O.M., Evdokimova O.V., Evdokimov S.M. On Taking into Account the Types of Sources and Settling Zones of Pollutants. Doklady Mathematics, 2000, vol. 61, no. 2, pp. 283-285.

4. Kalinina E.A. A Numerical Study of an Inverse Problem of Recovering the Heat Source for the Two-Dimensional Nonstationary Convection-Diffusion Equation. Far Eastern Mathematical Journal, 2004, vol. 5, no. 1, pp. 89-99. (in Russian)

5. Kriksin Yu.A., Plushchev S.N., Samarskaya E.A., Toshkin V.F. Inverse Problem of Recovering the Source Density for a Convection-Diffusion Equation. Matematicheskoe Modelirovanie [Mathematical Modelling], 1995, vol. 7, no. 11, pp. 95-108. (in Russian)

6. Iskenderov A.D., Akhundov A.Ya. Inverse Problem for a Linear System of Parabolic Equations. Doklady Mathematics, 2009, vol. 79, no. 1, pp. 73-75. DOI: $10.1134 /$ S1064562409010219

7. Ismailov M.I., Kanca F. Inverse Problem of Finding the Time-Dependent Coefficient of Heat Equation from Integral Overdetermination Condition Data. Inverse Problems In Science and Engineering, 2012, vol. 20, no. 24, pp. 463-476. 
8. Ivanchov M.I. Inverse Problem of Simulataneous Determination of Two Coefficients in a Parabolic Equation. Ukrainian Mathematical Journal, 2000, vol. 52, no. 3, pp. 379-387. DOI: 10.1007/BF02513132

9. Jing Li, Youjun Xu. An Inverse Coefficient Problem with Nonlinear Parabolic Equation. Journal of Applied Mathematics and Computing, 2010, vol. 34, no. 1-2, pp. 195-206. DOI: $10.1007 / \mathrm{s} 12190-009-0316-8$

10. Kamynin V.L., Franchini E. An Inverse Problem for a Higher-Order Parabolic Equation. Mathematical Notes, 1998, vol. 64, no. 5, pp. 590-599. DOI: $10.1007 / \mathrm{BF} 02316283$

11. Kerimov N.B., Ismailov M.I. An Inverse Coefficient Problem for the Heat Equation in the Case of Nonlocal Boundary Conditions. Journal of Mathematical Analysis and Applications, 2012, vol. 396, issue 2, pp. 546-554. DOI: 10.1016/j.jmaa.2012.06.046

12. Kozhanov A.I. Parabolic Equations with an Unknown Coeffiecient Depending on Time. Computational Mathematics and Mathematical Physics, 2005, vol. 45, no. 12, pp. 2085-2101.

13. Vasin I.A., Kamynin V.L. On the Asymptotic Behavior of Solutions to Inverse Problems for Parabolic Equations. Siberian Mathematical Journal, 1997, vol. 38, no. 4, pp. 647-662. DOI: $10.1007 /$ BF02674572

14. Prilepko A.I., Orlovsky D.G., Vasin I.A. Methods for solving inverse problems in Mathematical Physics. New-York, Marcel Dekker, Inc. 1999.

15. Tryanin A.P. Determination of Heat-Transfer Coefficients at the Inlet into a Porous Body and Inside It by Solving the Inverse Problem. Journal of Engineering Physics, 1987, vol. 52, no. 3, pp. 346-351. DOI: 10.1007/BF00872521

16. Dehghan M., Shakeri F. Method of Lines Solutions of the Parabolic Inverse Problem with an Overspecification at a Points. Numerical Algorithms, 2009, vol. 50, no. 4, pp. 417-437. DOI: $10.1007 / \mathrm{s} 11075-008-9234-3$

17. Pyatkov S.G., Samkov M.L. On Some Classes of Coefficient Inverse Problems for Parabolic Systems of Equations. Sib. Adv. in Math., 2012, vol. 22, no. 4, pp. 287-302. DOI: $10.3103 /$ S1055134412040050

18. Pyatkov S.G. On Some Classes of Inverse Problems for Parabolic Equations. Journal of Inverse Ill-Posed problems, 2011, vol. 18, no. 8, pp. 917-934. DOI: $10.1515 /$ jiip.2011.011

19. Ivanchov M. Inverse Problems for Equations of Parabolic Type Math. Studies. Monograph Series. V. 10. Lviv, WNTL Publishers, 2003.

20. Kabanikhin S.I. Obratnye $i$ nekorektnye zadachi [Inverse and Illl-posed problems]. Novosibirsk, Sibirskoe Nauchn. Izdat., 2009. 457 p.

21. Triebel H. Interpolation Theory, Function Spaces, Differential Operators. NorthHolland Mathematical Library, 18. Amsterdam, North-Holland Publishing, 1978.

22. Amann H. Compact Embeddings of Vector-Valued Sobolev and Besov Spaces. Glasnik matematicki, 2000. vol. 35, no. 55, pp. 161-177.

23. Amann H. Operator-Valued Foutier Multipliers, Vector-Valued Besov Spaces and Applications. Mathematische Nachrichten, 1997, vol. 186, no. 1, pp. 5-56. DOI: $10.1002 /$ mana.3211860102 
24. Amann H. Linear and Quasilinear Parabolic Problems. V. I. Basel, Boston, Berlin, Birkhauser Verlag, 1995. DOI: 10.1007/978-3-0348-9221-6

25. Ladyzhenskaya O.A., Solonnikov V.A., Ural'tseva N.N. Lineynye $i$ kvazilineynye uravneniya parabolicheskogo tipa [Linear and Quasilinear Equations of the Parabolic Type]. Moscow, Nauka, 1967.

26. Ladyzhenskaya O.A., Ural'tseva N.N. Lineynye $i$ kvazilineynye uravneniya ellipticheskogo tipa [Linear and Quasilinear Elliptic Equation of the Elliptic Type]. Moscow, Nauka, 1973.

27. Alifanov O.M., Artyukhov E.A., Nenarokom A.V. Obratnye zadachi slozhnogo teploobmena [Inverse Problems of Complicated Heat Exchange]. Moscow, Yanus-K, 2009.

28. Alifanov O.M. Inverse Heat Transfer Problems. Springer-Verlag, Berlin Heidelberg, 1994. DOI: $10.1007 / 978-3-642-76436-3$

29. Ozisik M.N., Orlando H.A.B. Inverse Heat Transfer. New-York, Taylor \& Francis, 2000.

Received September 9, 2014

\title{
НЕКОТОРЫЕ ОБРАТНЫЕ ЗАДАЧИ ДЛЯ СИСТЕМ УРАВНЕНИЙ КОНВЕКЦИИ-ДИФФУЗИИ
}

\author{
С.Г. Пятков, Е.И. Сафонов
}

В настоящей статье мы рассмотрим вопросы корректности некоторых обратных задач для математических моделей процессов тепломассопереноса и конвекциидиффузии. Коэффициенты и правая часть системы восстанавливаются при выполнении некоторых дополнительных условий переопределения. Эти условия есть значения интегралов решения с весами по некоторой совокупностью областей. Доказаны теоремы существования и единственности и установлены оценки устойчивости. Полученные результаты являются локальными по времени. В качестве основных функциональньх пространств используются пространства Соболева. Результаты служат основой при обосновании сходимости численных алгоритмов решения обратных задач с точечными условиями переопределения, которые возникают, в частности, в задачах тепломассопереноса об определении функции источников и параметров среды.

Ключевые слова: параболические системы; конвекчия-диффузия; тепломассоперенос; обратная задача; задача управления; краевая задача; корректность.

\section{Литература}

1. Алексеев, Г.В. Оптимизация в стационарных задачах тепломассопереноса и магнитной гидродинамики / Г.В. Алексеев. - М.: Науч. мир, 2010.

2. Belov, Ya.Ya. Inverse Problems for Parabolic Equations / Ya.Ya. Belov. - Utrecht: VSP, 2002. 
3. Babeshko, O.M. On taking into account the types of sources and settling zones of pollutants / O.M. Babeshko, O.V. Evdokimova, S.M. Evdokimov // Doklady Mathematics. - 2000. - V. 61, № 2. - P. 283-285.

4. Калинина, Е.А. Численное исследование обратной задачи восстановления плотности источника двумерного нестационарного уравнения конвекции-диффузии / Е.А. Калинина // Дальневосточный математический журнал. - 2004. - Т. 5, № 1. - C. 89-99.

5. Обратная задача восстановления плотности источника для уравнения конвекциидиффузии / Ю.А. Криксин, С.Н. Плющев, Е.А. Самарская, В.Ф. Тишкин // Математическое моделирование. - 1995. - Т. 7, № 11. - С. 95-108.

6. Iskenderov, A.D. Inverse Problem for a Linear System of Parabolic Equations A.D. Iskenderov, A.Ya. Akhundov // Doklady Mathematics. - 2009. - T. 79, № 1. - P. $73-75$.

7. Ismailov, M.I. Inverse Problem of Finding the Time-Dependent Coefficient of Heat Equation from Integral Overdetermination Condition Data / M.I. Ismailov, F. Kanca // Inverse Problems In Science and Engineering. - 2012. - V. 20, № 24. - P. 463-476.

8. Ivanchov, M.I. Inverse Problem of Simulataneous Determination of Two Coefficients in a Parabolic Equation / M.I. Ivanchov // Ukrainian Mathematical Journal. - 2000. - V. 52, № 3. - P. 379-387.

9. Jing, Li. An Inverse Coefficient Problem with Nonlinear Parabolic Equation / Jing Li, Youjun Xu // Journal of Applied Mathematics and Computing. - 2010. - V. 34, № 1-2. - P. 195-206.

10. Kamynin, V.L. An Inverse Problem for a Higher-Order Parabolic Equation / V.L. Kamynin, E. Franchini // Mathematical Notes. - 1998. - V. 64, № 5. - P. 590-599.

11. Kerimov, N.B. An Inverse Coefficient Problem for the Heat Equation in the Case of Nonlocal Boundary Conditions / N.B. Kerimov, M.I. Ismailov // Journal of Mathematical Analysis and Applications. - 2012. -V. 396, issue 2. - P. 546-554.

12. Кожанов, А.И. Параболические уравнения с неизвестным коэффициентом, зависящим от времени / А.И. Кожанов // Журнал вычислительной математики и математической физики. - 2005. - Т. 45, № 12. - С. 2168-2184.

13. Vasin, I.A. On the Asymptotic Behavior of Solutions to Inverse Problems for Parabolic Equations / I.A. Vasin, V.L. Kamynin // Siberian Mathematical Journal. - 1997. V. 38, № 4. - P. 647-662.

14. Prilepko, A.I. Methods for solving inverse problems in Mathematical Physics A.I. Prilepko, D.G. Orlovsky, I.A. Vasin. - New-York: Marcel Dekker, Inc. 1999.

15. Tryanin, A.P. Determination of Heat-Transfer Coefficients at the Inlet into a Porous Body and Inside It by Solving the Inverse Problem / A.P. Tryanin // Journal of Engineering Physics. - 1987. - V. 52, № 3. - P. 346-351.

16. Dehghan, M. Method of Lines Solutions of the Parabolic Inverse Problem with an Overspecification at a Points / M. Dehghan, F. Shakeri // Numerical Algorithms. 2009. - V. 50, № 4. - P. 417-437. 
17. Pyatkov, S.G. On Some Classes of Coefficient Inverse Problems for Parabolic Systems of Equations / S.G. Pyatkov, M.L. Samkov // Sib. Adv. in Math. - 2012. - V. 22, № 4. - P. 287-302.

18. Pyatkov, S.G. On Some Classes of Inverse Problems for Parabolic Equations S.G. Pyatkov // Journal of Inverse Ill-Posed problems. - 2011. - V. 18, № 8. P. 917-934.

19. Ivanchov M. Inverse Problems for Equations of Parabolic Type Math. Studies. Monograph Series. V. 10 / M. Ivanchov. - Lviv: WNTL Publishers, 2003.

20. Кабанихин, С.И. Обратные и некоректные задачи / С.И. Кабанихин. - Новосибирск: Сибирское научное издательство, 2009. - 457 с.

21. Triebel, H. Interpolation Theory, Function Spaces, Differential Operators. NorthHolland Mathematical Library, 18 / H. Triebel. - Amsterdam: North-Holland Publishing, 1978.

22. Amann, H. Compact Embeddings of Vector-Valued Sobolev and Besov Spaces H. Amann // Glasnik matematicki. - 2000. - V. 35, № (55). - P. 161-177.

23. Amann, H. Operator-Valued Foutier Multipliers, Vector-Valued Besov Spaces and Applications / H. Amann // Mathematische Nachrichten. - 1997. - V. 186, № 1. - P. 5-56.

24. Amann, H. Linear and Quasilinear Parabolic Problems. V. I. / H. Amann. - Basel; Boston; Berlin: Birkhauser Verlag, 1995.

25. Ладыженская, О.А. Линейные и квазилинейные уравнения параболического типа / О.А. Ладыженская, В.А. Солонников, Н.Н. Уральцева. - М.: Наука, 1967.

26. Ладыженская, О.А. Линейные и квазилинейные уравнения эллиптического типа / О.А. Ладыженская, Н.Н. Уральцева. - М.: Наука, 1973.

27. Алифанов, О.М. Обратные задачи сложного теплообмена / О.М. Алифанов, Е.А. Артюхов, А.В. Ненароком. - Москва: Янус-К, 2009.

28. Alifanov, O.M. Inverse Heat Transfer Problems / O.M. Alifanov. - Springer-Verlag. Berlin Heidelberg. 1994.

29. Ozisik, M.N. Inverse Heat Transfer / Ozisik M.N., Orlando H.A.B. - New-York: Taylor \& Francis, 2000.

Работа проводилась при финансовой поддержке Российского фонда фундаментальных исследований. Грант №12-01-00260а.

Сергей Григорьевич Пятков, доктор физико-математических наук, профессор, кафедра «Высшая математика», Югорский государственный университет (г. ХантыМансийск, Российская Федерация), s_pyatkov@ugrasu.ru.

Егор Иванович Сафонов, аспирант, кафедра «Высшая математика», Югорский государственный университет (г. Ханты-Мансийск, Российская Федерация), dc.gerz.hd@gmail.com.

Поступила в редакиию 9 сентября 20142. 